\title{
Pengaruh Program Kajian Remaja Terhadap Akhlak Siswa Kepada Guru di SMP Negeri 2 Gemolong Tahun Ajaran 2015/2016
}

\author{
Nida'ul Mufidah \\ SMP Negeri 2 Gemolong Sragen \\ e-mail: nidamufied@gmail.com
}

\begin{abstract}
The aims of the research are 1) to know the students attitudes who join teenager religious meeting program to the, 2) to know the students attitudes who do not join teenager religious meeting program to the teachers, 3) to know the influences of teenager religious meeting program to the students' attitude to the teachers. The methods of this research is kuantitatif ex post facto. The reasearch is held at SMP Negeri 2 Gemolong Sragen in August 2015 up to January 2016. The population of this research is 190 students of the seventh and eighth grades. The sample is 148 students of the seventh and eighth grades. The data is analyzed by using normality test requirement by using chi kuadrat formula, and hypothesis by using uji-t formula. We can conclude that 1) the students' attitude who join religious meeting program for teenager to the teachers is at medium category which are 40 students, 2) the students' attitude who do not join religious meeting program for teenager to the teachers is at medium category which are 108 students,3) the result of comparative analysis uji-t formula shows that the value of ( $t_{\text {hitung }} 11,588>t_{\text {tabel }}$ 1.960) which has significan level 5\%, therefore there are influnces of religious meeting program for teenager to the teachers.
\end{abstract}

Keyword: religious meeting program for teenager, students's attitude to teachers 


\section{Pendahuluan}

Agama Islam adalah agama universal yang mengajarkan kepada umat manusia mengenai berbagai aspek kehidupan baik kehidupan duniawi maupun ukhrawi.Salah satu diantara ajaran Islam tersebut adalah mewajibkan kepada umatnya untuk melaksanakan pendidikan karena menurut ajaran Islam pendidikan merupakan hidup mutlak yang harus dipenuhi, demi tercapainya kesejahteraan dan kebahagiaan dunia dan di akhirat, dengan berpendidikan manusia akan mendapatkan berbagai macam ilmu pengetahuan untuk bekal hidupnya.

Tujuan pendidikan menurut para ahli pendidikan Islam adalah mendidik akhlak dan jiwa anak didik, menanamkan rasa fadhilah (keutamaan), membiasakan dengan kesopanan yang tinggi, dan mempersiapkan mereka untuk suatu kehidupan yang suci seluhurnya ikhlas dan jujur (M.Athiyah Al-Abrasyi, 2003:1). Ali Abdul Halim Mahmud (2004:32), menyatakan akhlak adalah suatu sifat yang tertanam kuat dalam diri yang darinya terlahir perbuatan-perbuatan dengan mudah dan ringan tanpa perlu berfikir dan merenung. Akhlak disebut baik jika sifat tersebut terlahir perbuataperbuatan indah menurut akal dan syari'at. Akan tetapi, jika terlahir perbuatanperbuatan buruk, maka sifat tersebut dinamakan akhlak yang buruk.Setiap manusia memerlukan yang namanya akhlak.Baik itu anak-anak, remaja ataupun orang tua, karena manusia hidup bersosial.

Usia siswa SMP masuk dalam kelompok remaja. Sekolah merupakan institusi dimana siswa banyak bertemu dan bergaul dengan teman-teman sebaya, pada guru dan staf sekolah.Sehingga siswa banyak melakukan interaksi sosial, baik secara langsung maupun tidak langsung.Interaksi yang baik bisa dilihat dari sikap dan akhlak yang baik.Namun dewasa ini banyak terlihat akhlak siswa kepada guru yang jauh dari tugas seorang siswa kepada guru. Seperti yang terjadi di SMP Negeri 2 Gemolong, yang dikemukakan oleh guru BK (Bimbingan dan Konseling). Kasus yang pertama, terjadi di dalam kelas saat pelajaran Matematika, siswa tidak mengerjakan PR dan guru menyuruh mengerjakan ke depan juga tidak mau, setelah itu disuruh ke ruangan $\mathrm{BK}$ juga tidak mau malah melototi guru dan menentang perintah guru. Kedua, siswa membolos sudah beberapa hari.Saat ditanya oleh guru alasan tidak masuk sekolah, siswa menjawab dengan jawaban yang tidak sopan dan 
membentak guru dengan kata-kata kasar. Ketiga, saat tadarusan bersama-sama di sekitar halaman sekolah, guru memberikan renungan kepada siswa agar merenung. Di depan guru tersebut ada 2 siswa yang ramai sendiri, disuruh maju ke depan namun tidak mau malahan lari ke kamar mandi. (wawancara dengan guru BP, 27 Februari 2015).

Sekarang ini banyak sekolah setingkat SMP dan SMA di Indonesia mengadakan program beragama di sekolah, salah satunya di SMP Negeri 2 Gemolong sangat memperhatikan akhlak siswanya dengan mengadakan program kajian remaja, program keagamaan ini di luar jam pelajaran PAI sebagai tambahan pelajaran PAI. Guru Agama Islam bekerja sama dengan sekolah membuat program agar siswa dan siswinya mampu mempunyai pengetahuan agama yang baik juga praktik pengamalan agama di rumahnya dengan baik. Program kajian Islam ini berada di bawah organisasi ROHIS (Kerohanian Islam) di SMP, dengan sebutan IRMA (Ikatan Remaja Masjid SMP 2) di bawah departemen dakwah.

Tujuan penelitian ini adalah, untuk mengetahui: 1) akhlak siswa kepada guru yang mengikuti program kajian remaja di SMP Negeri 2 Gemolong, Sragen tahun ajaran 2015/2016. 2) akhlak siswa kepada guru yang tidak mengikuti program kajian remaja di SMP Negeri 2 Gemolong, Sragen tahun ajaran 2015/2016. 3) pengaruh program kajian remaja terhadap akhlak siswa kepada guru di SMP Negeri 2 Gemolong, Sragentahun ajaran 2015/2016

\section{Program Kajian}

Menurut Kamus Besar Bahasa Indonesia, program adalah rancangan asasasas serta dengan usaha yang akan dilakukan (Departemen Pendidikan Nasional, 2007:911). Secara bahasa kajian artinya diskusi atau membahas.Sedangkan menurut istilah diskusi atau pemahaman tentang sesuatu ilmu dengan metode tertentu.Selain itu kajian mempunyai beberapa arti, pertama, pengajaran (agama Islam). Kedua, berarti pembacaan Alqur'an, ketiga,berarti penyelidikan atau pengajaran yang mendalam (Depag RI, 1983:4).

Umat Islam perlu melakukan kajian ke-Islaman agar: 1) mempunyai wawasan yang luas tentang Islam baik dari aspek-aspek ajarannya maupun dari aspek 
mazhab/aliran/paham pemikirannya. 2) Umat Islam mempunyai sikap yang fleksibel jika berhadapan dengan pihak lain yang berbeda aliran/mazhabnya bahkan berbeda agama. 3) Umat Islam mempunyai sikap yang semakin toleran terhadap pihak lain berbeda pendapat. 3) Umat Islam mempunyai banyak alternatif untuk menganut salah satu pemikiran, mazhab atau pemahaman yang dianggap lebih sesuai dan menyakinkan jiwa dan pikirannya sesuai situasi, tempat dan zaman serta kondisi yang berkembang dinamis.

\section{Profil Program Kajian Remaja di SMP Negeri 2 Gemolong Sragen}

Untuk menjadikan sekolah yang peserta didiknya berakhlak dan berprestasi, SMP Negeri 2 Gemolong memberikan sarana agar menjadi wadah bagi mereka dengan program kegiatan yang bermanfaat.Sekolah membentuk program KAJIAN REMAJA SMP Negeri 2 gemolong di bawah tanggung jawab IRMA (Ikatan Remaja Masjid) SMP Negeri 2 Gemolong.Kajian remaja di sekolah ini merupakan wadah untuk siswa yang ingin mempelajari ilmu agama Islam dan menjadi remaja yang berakhlak Islami dan berprestasi. Adapun tujuannya adalah untuk mengajak remaja khususnya siswa SMP Negeri 2 Gemolong mejadi remaja yang berakhlakul karimah dan dapat mewarnai sekolahan dengan akhlak yang baik.

Menurut Hurlock (1980:206) secara etimologi, remaja berarti “tumbuh" atau “tumbuh menjadi dewasa”. Secara istilah yang diungkapkan oleh Piaget dalam buku Elizabeth B. Hurlock (1980:206) mengatakan bahwa: "Secara psikologis, masa remaja adalah usia di mana individu berintegrasi dengan masyarakat dewasa, usia di mana anak tidak lagi merasa di bawah tingkatan yang sama, sekurang-kurangnya dalam masalah bak Integrasi dalam masyarakat (dewasa) mempunyai banyak aspek efektif, kurang lebih berhubungan dengan masa puber". Termasuk juga perubahan intelektual yang mencolok. Transformasi intelektual yang khas dari cara berpikir remaja ini memunginkannya untuk mecapai integrasi dalam hubungan sosial orang dewasa, yang kenyataannya merupakan ciri khas yang umum dari periode perkembangan ini. 


\section{Akhlak Siswa Kepada Guru}

Menurut Abd. Rachman Assegaf (2011:42), kata akhlak berasal dari bahasa Arab akhlaq, berakar dari khalaqa yang berarti menciptakan. Seakar dengan kata khaliq (pencipta), makhluk (yang diciptakan), dan khaliq (penciptaan).

Menurut Marzuki (2012:173), di dalam Alqur'an hanya ditemukan bentuk tunggal dari akhlak yaitu khuluk(QS. al-Qalam (68): 4).

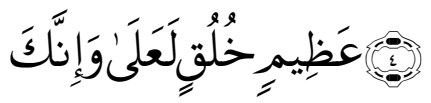

Artinya : Dan sesungguhnya engkau benar-benar, berbudi pekerti yang agung. (Depag RI, 2009:564)

Dasar atau landasan pokok akhlak adalah Al-qur'an dan Hadis. Al-qur'an dan hadis merupakan tolak ukur dari nilai akhlak Islam. Hal ini sebagaimana dikemukakan oleh Mustofa (1997: 149) bahwa: “Akhlak Islam, karena merupakan sistem akhlak yang berdasarkan kepada kepercayaan kepada Tuhan, maka tentunya sesuai pula dengan dasar dari pada agama itu sendiri. Dengan demikian, dasar atau sumber pokok daripada akhlak adalah Alqur'an dan Al-Hadisyang merupakan sumber utama dari agama itu sendiri”.

Oleh karena itu, sumber pokok akhlak yaitu Al-qur'an dan Al-Hadis.Dan ruang lingkup akhlak terbagi menjadi beberapa, salah satunya adalah akhlak kepada guru. Guru merupakan orang kedua yang harus dihormati dan dimuliakan setelah orang tua. Mereka menggantikan peran orangtua dalam mendidik siswa ketika berada di dalam lembaga pendidikan formal.Dengan demikian seharusnya siswa menghargai dan memuliakan para guru seperti halnya memuliakan orang tuanya (Heri Jauhari Muchtar, 2008: 150). Sehingga akhlakul karimah terhadap guru perlu diterapkan sebagaimana akhlak kita terhadap orang tua

\section{Faktor-Faktor Yang Mempengaruhi Ahlak Siawa}

Pada dasarnya setiap manusia memiliki keinginan untuk memiliki kepribadian yang baik. Nipa Abdul Halim (2004: 12) mengemukakan bahwa: "setiap orang ingin agar menjadi orang yang baik, mempunyai kepribadian yang kuat, dan 
sikap mental yang kuat dan akhlak yang terpuji. Semua itu dapat diusahakan dengan melalui pendidikan, untuk itu perlu dicari jalan yang dapat membawa kepada terjaminnya akhlak perilaku ihsan. Dengan demikian pendidikan agama harus diberikansecara terus-menerus baik faktor kepribadian, faktor keluarga, pendidikan formal, pendidikan nor-formal atau lingkungan masyarakat". Sehingga, secara umum ada beberapa faktor yang mempengaruhi akhlak antara lain faktor Internal dan faktor Ekaternal (Lingkungan Keluarga, Lingkungan Sekolah, Lingkungan Masyarakat. Sedangkan Bentuk-bentuk Akhlak Siswa Kepada Guru adalah: 1) memuliakan dan menghormati guru, 2) mematuhi perintah guru, 3) memahami tata karma dalam majlis ilmu

Pendidikan Agama merupakan salah satu mata pelajaran yang wajib didapatkan oleh setiap siswa-siswi di sekolah. Di sekolah negeri jam pelajaran PAI sangat minim yaitu hanya 2 jam pelajaran dalam seminggu, sehingga pengetahuan keagamaan siswa-siswi sangatlah minim dan berdampak dengan pemahaman agama dan akhlak siswa.Seiring perkembangan jaman di era modern ini, semakin banyak akhlak yang muncul di kalangan siswa sekolah yang mengarah pada kemerosotan akhlak. Ditandai dengan kejadian-kejadian disekolah, siswa banyak melanggar peraturan dan tatakrama kepada guru. Guru mereka anggap sebagai orang yang membosankan dan hanya memberikan perintah saja. Dan sekolah hanya mereka jadikan ajang untuk keluar dari rumah saja.

Sekolah dan guru memberikan sarana yang terbaik umtuk anak didiknya sesuai dengan kemampuan. Selain sekolah memberikan fasilitas pembelajaran juga memberikan tambahan seperti ekstrakulikuler maupun yang lain untuk menunjang prestasi dan akhlak siswa.

Salah satu sekolah negeri di SMP N 2 Gemolong melalui organisasi Ikatan Remaja Masjid mengadakan kegiatan rutin sepekan sekali yaitu Program kajian remaja Islam.Kegiatan Program kajian remaja Islam ini berada di bawah organisasi IRMA (Ikatan Remaja Masjid) di SMP Negeri 2 Gemolong. Dari program ini siswa dapat memperoleh ilmu agama yang lebih luas dan pemahaman yang lebih banyak. Materi yang dipelajari mencakup akhlak, aqidah, fiqh, qur'an hadis dan juga pengetahuan yang menunjang aplikasi dari agama Islam. Materi akhlak mencakup 
akhlak kepada orangtua dan guru. Dari pengetahuan agama yang semakin banyak diketahui oleh siswa makaakan terbentuknya akhlakul karimah kepada sesama terutama kepada guru.

Kegiatan ini sebagai tempat untuk berkumpul dan belajar mengkaji tentang agama Islam sebab jam pelajaran pendidikan agama Islam di sekolah negeri itu terbatas hanya satu kali tatap muka setiap minggunya. Semakin banyak materi yang didapatkan tentang pengetahuan agama Islam untuk peserta didik akan meningkatkan akhlak yang baik. Target dari program kajian remaja ini adalah membentuk akhlak yang baik kepada sesama manusia, baik kepada orangtua, teman sebaya, guru maupun masyarakat. Diharapkan ada pengaruh yang mendukung akhlak, dengan adanya program kajian remaja siswa dan siswi yang mengikuti program ini secara intensif satu minggu sekali dapat berakhlak yang baik kepada guru.

\section{Metode Penelitian}

Penelitian ini merupakan penelitian kuantitatif yaitu penelitian yang banyak dituntut menggunakan angka, mulai dari pengumpulan data, penafsiran terhadap data, serta penampilan dari hasilnya (Suharsimi Arikunto, 2006: 136). Dalam penelitian ini penulis menggunakan Dalam penelitian ini, menggunakan jenis kausal komparatif atau ex post facto.

Penelitian ini dilaksanakan di SMP Negeri 2 Gemolong, Sragen.Dipilihnya SMP Negeri 2 Gemolong dikarenakan sekolah tersebut ada program kajian remaja. Adapun waktu penelitian dimulai pada bulan Januari 2015-Januari 2016, dimulai dari persiapan penyusunan usulan penelitian, penelitian lapangan, pengumpulan data, analisis data dan penulisan laporan penelitian. Populasi dalam penelitian ini adalah siswa kelas VII dan VIII SMP Negeri 2 Gemolong yang berjumlah 190 siswa. Adapun yang menjadi sampel adalah siswa yang mengikuti program kajian remaja sebanyak 40 siswa.

Berdasarkan populasi dan sampel siswa yang mengikuti program kajian remaja maka teknik sampling yang digunakan adalah total sampling. Menurut Sugiyono (2007: 66) total sampling adalah teknik pengambilan sampel dimana jumlah sampel dengan dengan jumlah populasi, untuk siswa yang mengikuti program 
kajian remaja yaitu 40 siswa. Menurut Sugiyono (2007 : 64) Proportionate Stratified Random Sampling adalah teknik yang digunakan bila populasi mempunyai anggota/unsur yang tidak homogen dan berstrata secara proposional. Sesuai dengan tabel Krejce penentuan jumlah sampel dari populasi siswa yang tidak mengikuti program kajian dengan taraf kesalahan 5\% dari jumlah siswa 150 mendapatkan 108 siswa.

Instrumen yang digunakan dalam penelian ini adalah berupa angket atau kuosioner. Angket atau kuosioner adalah sejumlah pertanyaan tertulis yang digunakan untuk memperoleh informasi dari responden dalam arti laporan tentang pribadinya, atau hal-hal yang ia ketahui (Suharsimi Arikunto, 2006;151).

Untuk menguji kebenaran hipotesis, digunakan metode statistik dengan menggunakan rumus Uji $t$ yaitu:

$$
\begin{aligned}
t & =\frac{\overline{x_{1}}-\bar{x}_{2}}{\sqrt{\frac{S^{2}}{n_{1}}+\frac{S^{2}}{n_{2}}}} \\
s^{2} & =\frac{\left[\Sigma f x_{1}^{2}-\frac{\left(\Sigma f x_{1}\right)^{2}}{n_{1}}\right]+\left[\Sigma f x_{2}^{2}-\frac{\left(\Sigma f x_{2}\right)^{2}}{n_{2}}\right]}{n_{1}+n_{2}-2}
\end{aligned}
$$

Atau:

$$
t=\frac{\overline{x_{1}}-\bar{x}_{2}}{\sqrt{\left(\frac{\left.\left(n_{1}-1\right) s_{1}^{2}+\left(n_{2}-1\right) s_{2}^{2}\right)}{n_{1}+n_{2}-2}\left(\frac{1}{n_{1}}+\frac{1}{n_{2}}\right)\right.}}
$$

(Sugiyono, 2010: 142).

Untuk mengetahui hipotesis (bila taraf kesalahan ditetapkan 5\% dan taraf kepercayaan 95\%), adalah sebagai berikut:

1) Jika harga $t_{\text {hitung }}>$ harga $t_{\text {tabel }}$ maka $H_{o}$ ditolak dan $H_{a}$ diterima, berarti ada pengaruh program kajian ramaja terhadap akhlak siswa kepada guru kelas VII dan VIII DI smp Negeri 2 Gemolong tahun pelajaran 2015/2016. 
2) Jika harga $t_{\text {hitung }}<$ harga $t_{\text {tabel }}$ maka $H_{o}$ diterima dan $H_{a}$ ditolak, berarti tidak ada pengaruh program kajian ramaja terhadap akhlak siswa kepada guru kelas VII dan VIII DI smp Negeri 2 Gemolong tahun pelajaran 2015/2016.

\section{Hasil Penelitian}

Penelitian dengan judul Pengaruh Program Kajian Remaja terhadap Siswa Kepada Guru pada siswa kelas VII dan VIII di SMP Negeri 2 Gemolong Sragen Tahun Ajaran 2015/2016 dengan menggunakan sampel 190 dapat disajikan data sebagai berikut:

1. Siswa yang mengikuti program kajian remaja

Berdasarkan skor penelitian dari variabel siswa yang mengikuti program kajian remaja diperoleh deskripsi data penelitian sebagai berikut:

Tabel 1. Data Distribusi Frekuensi siswa yang mengikuti program kajian remaja

\begin{tabular}{|c|c|c|c|}
\hline Kelas Interval & Frekuensi & $\mathbf{\%}$ & kategori \\
\hline $65-72$ & 5 & 12.5 & Rendah \\
\hline $73-80$ & 24 & 60 & Sedang \\
\hline $81-88$ & 11 & 27.5 & Tinggi \\
\hline Jumlah & 40 & 100 & \\
\hline
\end{tabular}

Berdasarkan tabel 1 di atas maka dapat disimpulkan bahwa frekuensi tertinggi siswa yang mengikuti program kajian remaja terdapat pada kelas interval yaitu 73 - 80 dengan frekuensi sebanyak 24 siswa dengan persentase $60 \%$ maka dapat disimpulkan bahwa nilai akhlak siswa kepada guru siswa yang mengikuti program kajian remaja pada kelas VII dan VIII tergolong sedang. Untuk lebih jelasnya dapat dilihat pada gambar berikut ini:

2. Siswa yang tidak mengikuti program kajian remaja

Berdasarkan skor penelitian dari variabel siswa yang tidak mengikuti kajian remaja pada siswa kelas VII dan VIII di SMP Negeri 2 Gemolong Sragen tahun ajaran 2015/2016 diperoleh deskripsi data penelitian sebagai berikut: 
Tabel 2. Kategori distribusi frekuensi siswa yang tidak mengikuti kajian remaja

\begin{tabular}{|c|c|c|c|}
\hline Kelas Interval & Frekuensi & $\%$ & kategori \\
\hline $45-55$ & 18 & 16.667 & Rendah \\
\hline $56-66$ & 67 & 62.037 & Sedang \\
\hline $67-77$ & 23 & 21.296 & Tinggi \\
\hline jumlah & 108 & 100 & \\
\hline
\end{tabular}

Berdasarkan tabel 2, diketahui bahwa frekuensi tertinggi akhlak siswa kepada guru siswa yang tidak mengikuti program kajian remaja terdapat pada kelas interval yaitu 56-66 dengan frekuensi sebanyak 67 siswa dengan persentase $62,037 \%$, frekuensi terendah terdapat pada kelas interval 45-55 sebanyak 18 siswa dengan prosentase $16,667 \%$, maka dapat disimpulkan bahwa akhlak siswa kepada guru siswa yang tidak mengikuti program kajian remaja pada siswa kelas VII dan VIII di SMP Negeri 2 Gemolong Sragen tahun ajaran 2015/2016 tergolong sedang.

Uji Normalitas digunakan untuk mengetahui apakah sampel data yang digunakan berasal dari populasi yang berdistribusi normal atau tidak. Dengan menggunakan Chi Kuadrat $\left(\chi^{2}\right)$ yang selanjutnya harga $\chi^{2}$ dikonsultasikan dengan $x^{2}$ tabel.

1. Siswa yang mengikuti program kajian remaja (x1)

Tabel 3. Data Perhitungan $\chi^{2}$ siswa yang mengikuti program kajian

\begin{tabular}{|c|c|c|r|r|r|r|}
\hline No & Interval & \multicolumn{1}{c|}{ fo } & \multicolumn{1}{c|}{ fh } & fo-fh & $\mathbf{( f o - f h}^{\wedge} \mathbf{2}$ & $\mathbf{( f o - f h )}^{\wedge} \mathbf{2} / \mathbf{f h}$ \\
\hline 1 & $65-68$ & 2 & 1 & 1 & 1 & 1.3133 \\
\hline 2 & $69-72$ & 3 & 5 & -2 & 6 & 1.0750 \\
\hline 3 & $73-76$ & 10 & 14 & -4 & 13 & 0.9769 \\
\hline 4 & $77-80$ & 14 & 14 & 0 & 0 & 0.0089 \\
\hline 5 & $81-84$ & 8 & 5 & 3 & 7 & 1.2376 \\
\hline 6 & $85-88$ & 3 & 1 & 2 & 4 & 4.8199 \\
\hline Jumlah & & 40 & 40 & 0 & 32 & 9.4315 \\
\hline
\end{tabular}




$$
\begin{aligned}
\chi^{2} & =\sum_{i=1}^{k} \frac{\left(\mathrm{f}_{0}-\mathrm{f}_{\mathrm{h}}\right)^{2}}{\mathrm{f}_{\mathrm{h}}} \\
& =9,431529 \\
\mathrm{Dk} & =6-1 \\
& =5, \chi^{2} \text { tabel }(11.070)
\end{aligned}
$$

Dari hasil perhitungan dapat diketahui bahwa $\chi^{2}$ hitung $9,431529<\chi^{2}$ tabel 11.070 dengan taraf signifikansi 5\% maka dapat disimpulkan sebaran angket siswa yang mengikuti program kajian remaja pada siswa kelas VII dan VIII di SMP Negeri 2 Gemolong Sragen Tahun Ajaran 2015/2016 dalam penelitian ini berdistribusi normal.

2. Siswa yang tidak mengikuti program kajian remaja (x2)

Tabel 4. Data Perhitungan $\chi^{2}$ siswa yang tidak mengikuti program kajian remaja

\begin{tabular}{|c|c|c|c|c|c|c|}
\hline No & Interval & Fo & fh & fo-fh & (fo-fh) $^{\wedge} \mathbf{2}$ & (fo-fh) $^{\wedge} \mathbf{2} / \mathbf{f h}$ \\
\hline 1 & $45-50$ & 6 & 2 & 4 & 13 & 5.1359 \\
\hline 2 & $51-56$ & 13 & 15 & -2 & 3 & 0.1779 \\
\hline 3 & $57-62$ & 37 & 37 & 0 & 0 & 0.0005 \\
\hline 4 & $63-68$ & 35 & 37 & -2 & 3 & 0.0939 \\
\hline 5 & $69-74$ & 14 & 15 & -1 & 0 & 0.0257 \\
\hline 6 & $75-80$ & 3 & 2 & 1 & 0 & 0.1227 \\
\hline jumlah & & 108 & 108 & 0 & 19 & 5.5565708 \\
\hline
\end{tabular}

$$
\begin{aligned}
x^{2} & =\sum_{i=1}^{k} \frac{\left(\mathrm{f}_{0}-\mathrm{f}_{\mathrm{h}}\right)^{2}}{\mathrm{f}_{\mathrm{ll}}} \\
& =5,556 \\
\mathrm{Dk} & =6-1 \\
& =5, x^{2} \text { tabel }(11.070)
\end{aligned}
$$

Dari hasil tersebut dapat diketahui bahwa $\chi^{2}$ hitung 5,556> $\chi^{2}$ tabel 11.070 dengan taraf signifikansi 5\% maka dapat disimpulkan sebaran data tentang siswa 
yang tidak mengikuti program kajian remaja pada siswa kelas VII dan VIII di SMP Negeri 2 Gemolong Sragen Tahun Ajaran 2015/2016 dalam penelitian ini berdistribusi normal.

Uji Homogenitas digunakan untuk mengetahui apakah sampel data yang digunakan berasal dari populasi yang berhomogen atau tidak. Dengan cara menghitung harga diperoleh $\mathrm{F}$ hitung $(1,377)$ sedangkan $\mathrm{F}$ tabel untuk dk pembilang 107 dan dk penyebut $40=0,05$ adalah 1,61. Jadi Fhitung $(1.377)<$ Ftabel $(1,97)$, sehingga Ho diterima artinya homogen. Ketentua rumus jika $\mathrm{n}_{1} \neq \mathrm{n}_{2}$, varian homogen dapat menggunakan rumus $2, \mathrm{dk}=\mathrm{n}_{1}+\mathrm{n}_{2}-2$.

Untuk menganalisa data yang telah terkumpul dari hasil penelitian dan menguji hipotesis apakah terdapat pengaruh akhlak siswa kepada guru terhadap program kajian remaja dengan menggunakan uji t:

$$
\begin{aligned}
& t=\frac{\overline{x_{1}}-\bar{x}_{2}}{\sqrt{\left(\frac{\left(n_{1}-1\right) s_{1}^{2}+\left(n_{2}-1\right) s_{2}^{2}}{n_{1}+n_{2}-2}\right)\left(\frac{1}{n_{1}}+\frac{1}{n_{2}}\right)}} \\
& t=\frac{77.475-61.58}{\sqrt{\left(\frac{(40-1) 24.050+(108-1) 45.61}{40+108-2}\right)\left(\frac{1}{40}+\frac{1}{108}\right)}} \\
& t=\frac{15.982}{\sqrt{\left(\frac{(39) 24.050+(107) 45.61}{106}\right)(0.054)}} \\
& t=\frac{15.482}{\sqrt{\left(\frac{937.973+4880.27}{106}\right)(0.034)}} \\
& t=\frac{15.982}{\sqrt{1.8805}} \\
& t=\frac{15.982}{1.371} \\
& t=11.583
\end{aligned}
$$

Berdasarkan analisis secara statistik, harga $\mathrm{t}$ hitung adalah 11,588. Selanjutnya $\mathrm{t}$ hitung dibandingkan dengan $\mathrm{t}$ tabel, untuk $\mathrm{dk}=\mathrm{n}_{1}+\mathrm{n}_{2}-2=40+108$ $-2=146$, dengan taraf kesalahan 0,05 maka harga $t$ tabel $=1,960$. Dengan demikian 
t hitung $(11,588)>\mathrm{t}$ tabel $(1,960)$, dapat diartikan Ho ditolak dan Ha diterima. Hal ini berarti bahwa terdapat pengaruh program kajian remaja terhadap akhlak siswa kepada guru.

Berdasarkan hasil penelitian analisis unit terhadap responden menunjukkan bahwa akhlak siswa kepada guru bagi siswa yang mengikuti program kajian remaja mempunyai nilai mean 77.7, median 77.928, modus 77.7 dan standar deviasi 4,90414, hal ini menunjukkan bahwa rata-rata akhlak siswa kepada guru bagi siswa yang mengikuti program kajian remaja pada kelas VII dan VIII di SMP Negeri 2 Gemolong Sragen Tahun Ajaran 2015/2016 menunjukkan akhlaknya baik.

Kebiasaan akhlak siswa kepada guru bagi siswa yang tidak mengikuti program kajian remaja mempunyai nilai mean 61,532, median 61,78, modus 61,78 dan standar deviasi 6,753. hal ini menunjukkan bahwa rata-rata akhlak siswa kepada guru bagi siswa yang tidak mengikuti program kajian remaja pada kelas VII dan VIII di SMP Negeri 2 Gemolong Sragen Tahun Ajaran 2015/2016 menunjukkan akhlaknya kurang.

Berdasarkan hasil hipotesis penelitian diperoleh t hitung $=11,588$ sedangkan nilai $\mathrm{t}$ table $=1.960$, hal ini menunjukkan terdapat pengaruh program kajian remaja terhadap akhlak siswa kepada guru pada siswa kelas VII dan VIII di SMP Negeri 2 Gemolong Sragen Tahun Ajaran 2015/2016.

Dapat dikatakan bahwa Prgram Kajian Remaja terbukti efektif untuk memberikan dan mengontol akhlak siswa kepada guru. Ini dikarenakan siswa-siswi lebih mengetahui dan memahami Islam sesuai dengan Alqur'an dan Hadist, mereka lebih dapat membedakan mana baik buruk dan dosa atau pahala.materi yang dipelajaripun mencakup fiqh, aqidah, akhlak, Al-qur'an maupun Hadis. Mereka dapat berdiskusi dan menanyakan sesuatu yang mereka lihat atau alami dengan jawaban sesuai dengan kebenaran Alqur'an dan Hadis. Siswa siswi lebih faham dan di aplikasikan dalam kehidupan sehati-hari.

Berdasarkan penelitian yang telah dilakukan pada siswa kelas VII dan VIII di SMP Negeri 2 Gemolong Sragen Tahun Ajaran 2015/2016 menunjukkan bahwa ada pengaruh program kajian remaja terhadap akhlak siswa kepada guru. Dari pembahasan diatas dengan keikutsertaan siswa dalam program kajian remaja dapat 
memberikan efek yang positif bagi peningkatan akhlak siswa kepada guru ditandai dengan skornya yang lebih tinggi. Sehingga keputusan hipotesis menyatakan bahwa ada pengaruh program kajian remaja terhadap akhlak siswa kepada guru di SMP Negeri 2 Gemolong, Sragen.

\section{Kesimpulan}

Berdasarkan data yang diperoleh dan analisis yang telah dilakukan, maka dapat disimpulkan bahwa:

1. Akhlak siswa kepada guru kelas VII dan VIII SMP negeri 2 Gemolong yang mengikuti program kajian remaja nilai mean 77.475 yang menunjukkan bahwa akhlak siswa kepada guru yang mengikuti program kajian remaja tersebut dalam kategori sedang.

2. Akhlak siswa kepada guru kelas VII dan VIII SMP negeri 2 Gemolong yang tidak mengikuti program kajian remaja nilai mean 61.532, median 61.78yang menunjukkan bahwa akhlak siswa kepada guru yang tidak mengikuti program kajian remaja tersebut dalam kategori sedang.

3. Berdasarkan perhitungan $\mathrm{t}$ test didapat $\mathrm{t}_{\text {hitung }} 11,588>\mathrm{t}_{\text {tabel }}$ 1.960. Jadi keputusan Uji Hipotesis adalah Ha diterima sehingga terdapat pengaruh program kajian remaja terhadap akhlak siswa kepada guru kelas VII dan VIII SMP negeri 2 Gemolong, Sragen tahun ajaran 2015/2016.

\section{Daftar Pustaka}

Assegaf, Abd. Rachman. 2011. Filsafat Pendidikan Islam. Jakarta: PT RajaGrafindo Persada

Ali Abdul Halim Mahmud. 2004. Akhlak Mulia. Jakarta: Gema Insani

Departemen Agama RI. 2004. Al Qur-an dan Terjemahannya. Bandung: CV Penerbit Diponegoro

Hurlock B. Elizabeth. 2005. Psikologi Perkembangan: Suatu Pendekatan Sepanjang Rentang Kehidupan. Jakarta: PT Gelora Aksara Pratama

Jauhari Muchtar, Heri. 2008. Fikih Pendidikan. Bandung: PT Remaja Rosdakarya 
John W. Santrock. 2007. Remaja. Edisi 11 Jilid 1. Jakarta: Erlangga

Khoiriyah. 2013. Metodologi Studi Islam. Surakarta: FATABA Press

Marzuki. 2012. Pembinaan Karakter Mahasiswa melalui Pendidikan Agama Islam di Perguruan Tinggi Umum. Yogyakarta: penerbit Ombak

M.Athiyah Al-Abrasyi. 2003. Dasar-dasar Pokok Pendidikan Islam. Jakarta: Bulan Bintang

Sarwono, Sarlito W. 2011. Psikologi Remaja. Jakarta: PT Raja Grafino Persada

Sugiyono. 2011. Metode Penelitian Kuantitatif, kualitatif dan kombinasi (mixed methods). Bandung: Alfabeta

Suharsimi Arikunto. 2006. Prosedur Penelitian. Jakarta: PT Rineka Cipta

Syamsu Yusuf. 2011. Psikologi Perkembangan Anak dan Remaja. Bandung: PT Remaja Rosdakarya

. 2012. Psikologi Perkembangan Anak dan Remaja. Bandung: PT Remaja Rosdakarya

Zakiah Daradjat. 1999. Metodik Khusus Pengajaran Agama Islam. Jakarta: Bumi Aksara. 
96 Nida'ul Mufidah

Pengaruh Program Kajian Remaja Terhadap Akhlak Siswa Kepada Guru di SMP Negeri 2 Gemolong Tahun Ajaran 2015/2016

| Volume. 2, No. 1, Januari-Juni 2017 